\title{
Definiendo el hacinamiento. Estándares normativos $y$ perspectivas judiciales sobre el espacio penitenciario
}

\author{
Assessing Overcrowding. Legal Standards and Judicial Perspectives on \\ Prison Space \\ Definindo a superlotação. Standards normativos e perspectivas judiciais \\ sobre o espaço penitenciário
}

\author{
Libardo José Ariza Higuera* \\ MARIO ANDRÉS TORRES GÓMEZ**
}

FECHA DE RECEPCIÓN: 31 DE ENERO DE 2019. FECHA DE APROBACIÓN: 10 DE ABRIL DE 2019

Doi: http://dx.doi.org/10.12804/revistas.urosario.edu.co/sociojuridicos/a.7632

Para citar: Ariza Higuera, L.J., \& Torres Gómez, M.A. (2019). Definiendo el hacinamiento. Estándares normativos y perspectivas juidicoales sobre el espacio penitenciario. Revista Socio-Jurídicos, 21(2), 227-258. Doi: http://dx.doi. org/10.12804/revistas.urosario.edu.co/sociojuridicos/a.7632

\section{RESUMEN}

En los últimos años, la crisis penitenciaria, en distintos países, ha ocupado un lugar central en las discusiones políticas, jurídicas y académicas. En el centro de estos debates se encuentra la cuestión del hacinamiento y su papel como principal indicador del desempeño penitenciario. No obstante, a pesar de su protagonismo, la definición del hacinamiento, así como su utilización en los modelos de intervención judicial, no es un asunto ampliamente debatido. En este texto proponemos un análisis del hacinamiento desde dos dimensiones; por una parte, una dimensión jurídica que responde a la pregunta de cómo medir el hacinamiento y, por otra, una dimensión práctica que busca mostrar cómo se pone en marcha en los procesos de judicialización de la vida en prisión.

Palabras clave: prisión, hacinamiento, política criminal, jueces, derechos humanos, estado de cosas inconstitucional, litigio estratégico

* Doctor en Derecho, Universidad de Deusto. Profesor Asociado y Director del Grupo de Prisiones, Universidad de los Andes. Bogotá, Colombia. Correo electrónico: Lj.ariza20@uniandes. edu.co. ORCID: http://orcid.org/0000-0002-4558-4332.

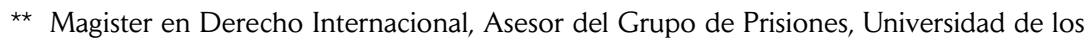
Andes; Profesor de Cátedra, Universidad Jorge Tadeo Lozano. Correo electrónico: Ma.torres1444@ uniandes.edu.co. ORCID: https://orcid.org/0000-0002-2011-8458. 


\section{ABSTRACT}

In recent years, the penitentiary crisis, in different countries, has occupied a central place in political, legal and academic discussions. At the center of these debates is the issue of overcrowding and its role as the essential indicator of prison performance. However, despite its prominence, its definition, as well as its use in models of judicial intervention, is not a widely debated issue. In this text, we propose an analysis of overcrowding from two perspectives: on the one hand, a legal dimension that answers the question of how to measure overcrowding and, on the other, a practical one that seeks to show its implementation in the processes of judicialization of life in prison.

Keywords: Prison, overcrowding, criminal policy, judges, human rights, unconstitutional state of affairs, strategic litigation.

\section{RESUMO}

Nos últimos anos, a crise penitenciária, em diferentes países, tem ocupado um lugar central nas discussões políticas, jurídicas e acadêmicas. No centro destes debates encontra-se a questão da superlotação e seu papel como principal indicador do desempenho penitenciário. No entanto, apesar de seu protagonismo, a definição da superlotação, assim quanto a sua utilização nos modelos de intervenção judicial, não é um assunto amplamente debatido. Neste texto, propomos uma análise da superlotação desde duas dimensões; por uma parte, uma dimensão jurídica que responde à pergunta de como medir a superlotação e, por outra, uma dimensão prática que busca mostrar como implementar os processos de judicialização da vida em prisão.

Palavras-chave: prisão, superlotação, política criminal, juízes, direito humanos, estado de cosas inconstitucional, litígio estratégico 


\section{Introducción}

En los últimos años, la intervención judicial en el mundo penitenciario ha adquirido un nuevo impulso, situando la discusión sobre la comprensión del significado y alcance de los derechos de los reclusos en un lugar central de la agenda constitucional. Desde el caso Verbitsky en Argentina (2005), pasando por el caso Brown vs Plata (2011) en los Estados Unidos, hasta la utilización de la doctrina del Estado de Cosas Inconstitucional en Colombia (Sentencias T-153 de 1998; T-388 de 2013; T-762 de 2015) y su adopción por los tribunales de Perú (2004) y Brasil (2015) para enfrentar la crisis carcelaria de sus respectivos contextos, la judicatura ha intervenido activamente frente a una de las instituciones más herméticas de las sociedades contemporáneas (González Bartomeu, Gargarella, 2016; CELS, 2008). El problema del hacinamiento ha ocupado un lugar preponderante en estos debates y, por ello, la discusión sobre cómo establecer y medir el hacinamiento como indicador de la gravedad de la crisis carcelaria, es uno de los asuntos centrales del control y seguimiento de las condiciones de reclusión de las personas privadas de la libertad.

En efecto, durante las últimas décadas, uno de los estándares más utilizados para medir la gravedad de la situación penitenciaria ha sido medir la capacidad oficial de alojamiento de los establecimientos para compararla con el número de personas privadas de la libertad. En la mayoría de los países, el uso del estándar de hacinamiento ha permitido presentar ante la opinión pública la gravedad de la situación penitenciaria, midiendo los avances y retrocesos en la consolidación de la política criminal y penitenciaria. En ese sentido, el seguimiento de los índices de hacinamiento ha sido una herramienta que consistentemente han usado jueces, congresistas, académicos, funcionarios públicos y miembros del sistema penitenciario para argumentar la necesidad de realizar modificaciones importantes en la política criminal y el sistema penitenciario, exigiendo una mayor inversión presupuestal en las cárceles, que permitan cumplir con la debida resocialización de las personas detenidas.

El objetivo fundamental de este artículo es mostrar el problema conceptual que supone definir el hacinamiento y su relación con los procesos de intervención judicial. Para ello, revisamos y describimos distintas aproximaciones al fenómeno en el ámbito comparado, mostrando que 
cada una de ellas supone una visión particular sobre el significado de la vida digna en prisión. A pesar de la intensa discusión que se ha dado sobre la definición del hacinamiento, como lo mostramos en este texto, en el contexto local la literatura especializada ha asumido una definición simple, que se basa en el resultado de comparar la capacidad teórica del sistema medida en cupos y el número de personas que este alberga, dejando de lado otras aproximaciones más exigentes en términos de garantía de derechos como, por ejemplo, una noción más amplia sobre condiciones adecuadas de reclusión.

En efecto, en el contexto regional, desde la aproximación pionera e influyente de Carranza (2001; 2012), ${ }^{1}$ importantes trabajos, como el de Hernández (2018), parten precisamente de esta visión simple del hacinamiento y a partir de esta proponen análisis sobre el impacto de la flexibilización del régimen de subrogados penales en la descongestión penitenciaria. Como este autor lo señala, "en cuanto al hacinamiento, este puede explicarse a partir de la diferencia existente entre el número de plazas o cupos y el número de internos" (2018, p. 89). ${ }^{2}$ Lo mismo puede encontrarse en otras aproximaciones, que asumen que el hacinamiento se presenta, "cuando la densidad penitenciaria es mayor que 100, porque hay más personas presas que la capacidad establecida para una prisión o para la totalidad del sistema" (Rodríguez, 2015, p. 139). Esta suerte de matemática del cupo, con las ventajas que supone a la hora de funcionar como un indicador simple y claro es la que ha dominado la orientación de la política criminal nacional con los resultados indeseados que se han observado en términos de expansión del sistema como principal remedio contra el hacinamiento, precisamente. $^{3}$

1 La siguiente es la definición presentada por Carranza: "Sobrepoblación crítica: Es la situación en que la densidad penitenciaria es igual a 120 o más. Adoptamos esta definición utilizada por el Comité Europeo para los problemas criminales como un criterio útil también para América Latina. Hacinamiento: Utilizamos este vocablo como sinónimo de sobrepoblación crítica" (2012, pp. 32-33).

2 En el mismo sentido, ver los trabajos de Archila y Hernández (2015) sobre el impacto de la reforma a los subrogados en el hacinamiento, y de Zorro, Acosta y Hernández (2016), desde una perspectiva un tanto distinta, sobre el impacto de la detención preventiva en la congestión penitenciaria.

3 Lo anterior, por supuesto, no quiere decir que este indicador carezca de utilidad práctica por su simpleza, precisamente. Lo que intentamos mostrar en este texto es que no puede asumirse con el descriptor único y principal para evaluar la relación entre espacio, personas y prisiones, desde una perspectiva de garantía amplia de derechos humanos. 
Esta discusión sobre la adecuada definición del hacinamiento, aunque estrechamente relacionada con el debate más amplio sobre los factores que pueden explicar el crecimiento de la población penitenciaria, especialmente en el contexto del encarcelamiento masivo (Blumstein, 1982; 2011; Pfaff, 2015), merece un debate importante en el contexto nacional para contribuir al proceso incitado por la Corte Constitucional en las sentencias T-388 de 2013 y T-762 de 2015. En efecto, la crítica a la visión dominante del hacinamiento, que la propia Corte Constitucional había defendido en la primera declaratoria de estado de cosas inconstitucional en la sentencia T-153 de 1998, se presenta claramente por la Corte años después, cuando señala que la intervención judicial no puede asumir que la causa de la violación masiva y sistemática de los derechos de las personas privadas de la libertad es el hacinamiento. ${ }^{4}$

Y, sin lugar a dudas, el giro hacía una visión compleja, integral de las condiciones de reclusión -dentro de la cual el acuerdo sobre la manera adecuada de definir el hacinamiento es un asunto clave-, se da definitivamente en la sentencia T-762 de 2015, ${ }^{5}$ que ordena la creación de las normas técnicas de reclusión y una línea base de indicadores (Ariza $\&$ Iturralde, 2017) que permita medir con mayor rigurosidad el desempeño estatal a la hora de garantizar un estándar constitucional de condiciones mínimas de reclusión. ${ }^{6}$ La formulación de la regla de equilibrio, como uno

4 En la sentencia T-388 de 2013, la Corte Constitucional reconoce el hacinamiento como un asunto integral que no se agota con la construcción de alojamientos. La Corte reconoce que, si bien los esfuerzos en la creación de una infraestructura entre 1998 y 2013 fueron en su mayoría exitosos, concluye que ésta ha sido una estrategia insuficiente ya que toda la inversión presupuestal se ha dirigido únicamente a la creación de nuevos cupos de alojamiento, abandonando la atención de otros aspectos clave del sistema como los programas de resocialización, la prestación de servicios de salud y agua potable, entre otros. Corte Constitucional, sentencia T-388 de 2013. M.P. María Victoria Calle.

5 Corte Constitucional, sentencia T-762 de 2015. M.P. Gloria Ortiz.

6 La Corte Constitucional en sentencia T- 762 de 2015 (orden vigésimo segunda, 20), ordena al Gobierno Nacional la creación de un Comité Interdisciplinario encargado de diseñar y aplicar las normas técnicas de reclusión, entre las cuales se encuentra la definición del hacinamiento. Sin embargo, a través del Auto 121 de 2018, la Corte encontró deficiencias significativas en la consolidación de sistemas de información y del diseño de indicadores y normas técnicas que permitan hacer seguimiento al hacinamiento. En efecto, desde expedición de la sentencia, los avances hacia la consolidación de una definición integral del hacinamiento han sido infructuosos. El Gobierno Nacional ha diseñado un primer borrador de normas técnicas de reclusión, pero estas no han sido implementadas en ningún establecimiento de reclusión de Colombia ni se reflejan en los sistemas de información de la política criminal. Como consecuencia, en la actualidad la cifra oficial de hacinamiento presentada por el INPEC sigue siendo elaborada 
de los horizontes de reforma penitenciaria más significativos impulsados por la intervención judicial contemporánea (Ariza \& Torres, 2019) debe basarse igualmente en una definición adecuada del hacinamiento, más allá del dato resultante de establecer la relación entre cupos y personas recluidas en un establecimiento o en un sistema penitenciario como un todo.

Teniendo en cuenta el lugar central que ha ocupado el hacinamiento en los procesos de intervención judicial en el mundo carcelario, en este texto quisiéramos analizar dos asuntos. En la primera parte del texto analizamos la dimensión jurídica y técnica del hacinamiento, esto es, la discusión normativa sobre cómo definirlo y la dificultad de establecer estándares de cumplimiento en materia de espacio y alojamiento. En la segunda parte del texto ubicamos esta discusión normativa en un contexto político más amplio, esto es, la manera en que el fenómeno global del encarcelamiento masivo $^{7}$ es resistido judicialmente, a través de la lucha contra el hacinamiento y su relación con la protección de los derechos de las personas privadas de la libertad. ${ }^{8}$ Concluimos con unas reflexiones en torno a los retos que supone el giro hacia la evaluación del espacio penitenciario en términos de alojamiento digno y adecuado, para ilustrar con mayor detalle los retos que supone la intervención judicial en esta materia.

\section{Midiendo el hacinamiento: estándares de alojamiento en el Derecho Internacional y Comparado}

El hacinamiento como medida de la crisis penitenciaria es ampliamente utilizado por los jueces y medios de comunicación cómo información básica

\footnotetext{
a partir de una visión simple, es decir, contando el número de personas encarceladas sobre el número de camas. el caso regional.

8 Para la elaboración de este documento realizamos una investigación sobre las principales fuentes jurídicas y estándares creados por sistemas nacionales e internacionales, así como decisiones judiciales que nos permitieran definir de forma integral y funcional el hacinamiento, identificando los aspectos relevantes que debe involucrar su medición en el contexto colombiano. De especial importancia resultaron los estudios técnicos sobre alojamiento en detención, antropometría y uso del espacio por parte de las personas recluidas y protocolos comparados sobre hacinamiento en diferentes jurisdicciones en donde existen normas técnicas de habitación en reclusión.
} 
de la gravedad de la crisis carcelaria; ${ }^{9}$ sin embargo, si hay algún acuerdo en la discusión normativa sobre el hacinamiento es que, paradójicamente, no existe un consenso claro sobre qué es exactamente y cómo se mide. Como lo señala Bleich (1989), se trata de un concepto profundamente elusivo que permite un amplio margen de movilidad política para los actores involucrados en el sistema quienes, con base en esta relativa flexibilidad, defienden versiones distintas de su alcance y significado.

La mayoría de los estudios sobre hacinamiento coinciden en que su definición no sólo varía teóricamente sino también contextualmente. La magnitud del fenómeno no sólo puede cambiar entre distintas regiones, sino que puede ser distinta de acuerdo con el tipo de establecimiento e incluso dentro de un mismo establecimiento (UNODC, 2013, p. 8). Como lo señala Albrecht, este problema de definición se desprende en gran parte de la ausencia de un conjunto de criterios internacionalmente aceptados, los cuales podrían ser usados para construir un instrumento que permita medir a los niveles de hacinamiento (Albrecht, 2012, p. 65). No obstante, el problema de definición no ha impedido el desarrollo de una amplia literatura sobre cómo reducir el hacinamiento y estabilizar los sistemas penitenciarios (Blumstein, 2011; Griffiths \& Murdoch, 2009; Clear \& Schrantz, 2011; European Commitee on Crime Problems, 2015; Davis \& Epperson, 2014; Bolduc, 1985). En lo que sigue de esta sección presentamos las principales aproximaciones al concepto de hacinamiento y revisamos las fuentes normativas que han sido empleadas para su definición.

\section{El hacinamiento como capacidad instalada}

Posiblemente la noción empleada más común de hacinamiento es aquella que parte de la capacidad instalada de un establecimiento o sistema y su comparación con el número de personas que alberga. Desde esta perspectiva, el hacinamiento es el resultado de una simple operación

9 Una revisión rápida del cubrimiento de la prensa estadounidense y latinoamericana sobre prisiones comprobará que el indicador por excelencia para explicar la crisis carcelaria es el índice de hacinamiento. Al analizar el uso político del discurso de hacinamiento, Jeff Bleich concluye que si bien todos los participantes de la política penitenciaria se encuentran interesados en reducir el hacinamiento, estos mismos participantes también usan activamente el discurso del hacinamiento para impulsar y justificar agendas políticas particulares (Bleich, 1989, p. 1128). 
cuantitativa en la que se establece el exceso de población, tomando como base el número de cupos que se han definido en los planos de diseño originales de los establecimientos (Mullen, 1985, pp. 34-36). Teniendo en cuenta que, por lo general, la demanda de cupos tiende a aumentar con relativa facilidad mientras que la oferta de celdas permanece relativamente estable, la tasa de hacinamiento tenderá a aumentar de manera constante. Esta perspectiva macro del fenómeno se concentra también en entender cuántas personas ingresan al sistema y durante cuánto tiempo permanecen en este en función de la capacidad instalada del mismo (Clear \& Schrantz, 2011, pp. 138-159). Como se verá más adelante, si bien estas discusiones son importantes para el diseño de la política pública, en el foro judicial se ha debatido ampliamente si esta aproximación al hacinamiento basta por sí sola como eje de un proceso de judicialización de las condiciones de reclusión.

En todo caso, entender un cupo carcelario como una cama y un espacio mínimo en un dormitorio resulta problemático, en la medida en que se deben tener en cuenta otros aspectos de la vida en prisión que van más allá de la ocupación de una celda. En otras palabras, un cupo carcelario integral no sólo comprende el espacio del dormitorio, también debe proveer la disponibilidad de un espacio común al aire libre, un espacio hidrosanitario con ducha y retrete, un espacio para comer y un espacio para actividades de resocialización. La aproximación al hacinamiento desde la densidad poblacional asume algunos de estos retos, como se verá en el siguiente apartado.

\section{El hacinamiento como densidad}

Otra perspectiva sobre el hacinamiento se enfoca en la relación entre la población intramural y el espacio que efectivamente pueden disfrutar. La cuestión no gira aquí en torno a la capacidad de albergue medida en celdas y cupos, sino en el espacio efectivamente disponible en un determinado establecimiento. Este giro hacia la densidad poblacional permite detectar, aunque sea tangencialmente, aspectos que una aproximación basada estrictamente en cupos parece obviar como, por ejemplo, la disponibilidad y el acceso a espacios comunes como talleres, aulas educativas o lugares deportivos, o incluso la vulnerabilidad a ciertas formas de 
violencia (Mullen, 1985, pp. 34-36). Puede que existan cupos, pero no suficiente espacio dentro de un establecimiento para que las personas puedan vivir en la cárcel, ya que la celda no es el único lugar en el que los internos pasarán sus días de privación de la libertad.

Para establecer la densidad poblacional como indicador de la relación se han propuesto estimaciones precisas. Así, por ejemplo, el Comité Internacional de la Cruz Roja (CICR), cuya función incluye la protección de las personas detenidas en el contexto del Derecho Internacional Humanitario, ha publicado un estudio sobre reglas técnicas en materia de alojamiento y servicios hidrosanitarios en prisiones llamado Agua, saneamiento y hábitat en las cárceles, que es ampliamente utilizado como manual de referencia para expresar una medición del hacinamiento (CICR, 2012). De acuerdo con el Comité Internacional de la Cruz Roja es importante calcular la tasa de ocupación (o densidad de población) como un estándar complementario de la tasa de hacinamiento, pues este refleja el espacio que efectivamente dispone la persona recluida en metros cuadrados (CICR, 2012, pp. 17-18).${ }^{10}$ El resultado arrojaría el número de metros cuadrados que cada recluso dispone en promedio, un indicador que es más claro sobre la cantidad de espacio efectivamente disponible que aquel que arroja la relación entre población albergada y capacidad instalada.

Además, la densidad poblacional dirige el análisis hacia una perspectiva más amplia e integral de la vida en prisión, en la cual el espacio penitenciario se evalúa en términos de las condiciones mínimas que deben cumplirse para garantizar la dignidad humana. Entonces, no se trata de medir únicamente la proporción entre cupos, personas presas y espacio disponible -aunque esto siga siendo importante- sino de las características que debe reunir un establecimiento de reclusión para ser jurídicamente aceptable. Este giro desde el debate por la sobrepoblación hacia los estándares de alojamiento digno se analiza en el siguiente apartado.

10 En consecuencia, la tasa de ocupación se calcularía mediante la siguiente fórmula: Tasa de ocupación $=$ número de detenidos presentes/capacidad oficial del alojamiento en $\mathrm{m}^{2}$. $(\mathrm{CICR}$, 2012, pp. 17-18). 


\section{Los estándares de alojamiento digno}

La medición integral del hacinamiento debe necesariamente preguntarse cuáles son las exigencias mínimas que debe cumplir un espacio de detención. En ese sentido, tanto el derecho internacional como diferentes estados y organizaciones internacionales han realizado importantes esfuerzos para definir arreglos normativos que incluyan jurídicamente esos requisitos mínimos que deben cumplir los establecimientos de reclusión. A continuación, se presentarán las exigencias centrales que incluyen los principales instrumentos.

Las Reglas Mínimas de las Naciones Unidas para el Tratamiento de los Reclusos, también llamadas "Reglas Nelson Mandela", son el instrumento internacional más comprensivo sobre la protección de las personas privadas de la libertad y es considerado actualmente como el estándar mínimo exigido por el Derecho Internacional y, por ejemplo, por la Corte Constitucional de Colombia para la protección de los reclusos. ${ }^{11}$ Tal como lo establece la observación preliminar 1 y 2 de las Reglas Mandela, este instrumento no ha sido redactado como un canon de normas que deben aplicar en todo momento, más pretende acordar reglas generalmente aceptadas en nuestro tiempo sobre los elementos esenciales de los sistemas penitenciarios contemporáneos. En materia de alojamiento, las Reglas que van de la 11 a la 21 establecen un catálogo de criterios mínimos bajo los cuales se deben regir los estándares de alojamiento, que se resumen en la siguiente tabla 1.

11 Las Reglas Mandela no son cómo tal un instrumento legal, en la medida en que las resoluciones de la Asamblea General de Naciones Unidas no son vinculantes ante los Estados miembros. Sin embargo, estas reglas suelen ser adoptadas por las legislaciones domésticas y algunas reglas pueden cristalizar la costumbre internacional (Rodley, 2011, p. 6). 
Tabla 1. Resumen de las Reglas Mandela en materia de alojamiento

\begin{tabular}{|c|c|c|}
\hline Fuente & Temática & Contenido Regla Mandela \\
\hline $\begin{array}{l}\text { Regla Mandela } \\
11\end{array}$ & $\begin{array}{l}\text { Separación entre } \\
\text { reclusos }\end{array}$ & $\begin{array}{l}\text { Los reclusos pertenecientes a categorías distintas deberán } \\
\text { ser alojados en establecimientos diferentes o en pabe- } \\
\text { llones diferentes dentro de un mismo establecimiento, } \\
\text { según su sexo y edad, sus antecedentes penales, los moti- } \\
\text { vos de su detención y el trato que corresponda aplicarles }\end{array}$ \\
\hline $\begin{array}{l}\text { Regla Mandela } \\
12\end{array}$ & Dormitorios & $\begin{array}{l}\text { 1. Cuando los dormitorios sean celdas o cuartos indi- } \\
\text { viduales, cada uno de estos será ocupado por un solo } \\
\text { recluso. Si por razones especiales, como el exceso tem- } \\
\text { poral de población reclusa, resulta indispensable que la } \\
\text { administración penitenciaria central haga excepciones a } \\
\text { esta regla, se evitará alojar a dos reclusos en una celda o } \\
\text { cuarto individual. } \\
\text { 2. Cuando se utilicen dormitorios colectivos, estos los } \\
\text { ocuparán reclusos que hayan sido cuidadosamente se- } \\
\text { leccionados y reconocidos como aptos para relacionarse } \\
\text { entre sí en esas condiciones. Por la noche se les somete- } \\
\text { rá a una vigilancia regular, adaptada al tipo de estableci- } \\
\text { miento de que se trate. }\end{array}$ \\
\hline $\begin{array}{l}\text { Regla Mandela } \\
13 \text { y } 14\end{array}$ & $\begin{array}{l}\text { Alojamiento: } \\
\text { Espacio, } \\
\text { iluminación, } \\
\text { ventilación }\end{array}$ & $\begin{array}{l}\text { Los locales de alojamiento de los reclusos, y especial- } \\
\text { mente los dormitorios, deberán cumplir todas las nor- } \\
\text { mas de higiene, particularmente en lo que respecta a } \\
\text { las condiciones climáticas y, en concreto, al volumen de } \\
\text { aire, la superficie mínima, la iluminación, la calefacción } \\
\text { y la ventilación. } \\
\text { En todo local donde vivan o trabajen reclusos: a) las } \\
\text { ventanas serán suficientemente grandes para que pue- } \\
\text { dan leer y trabajar con luz natural y estarán construidas } \\
\text { de manera que pueda entrar aire fresco, haya o no } \\
\text { ventilación artificial; b) la luz artificial será suficiente para } \\
\text { que puedan leer y trabajar sin perjudicarse la vista. }\end{array}$ \\
\hline $\begin{array}{l}\text { Regla Mandela } \\
15\end{array}$ & Hidrosanitarios & $\begin{array}{l}\text { Las instalaciones de saneamiento serán adecuadas para } \\
\text { que el recluso pueda satisfacer sus necesidades naturales } \\
\text { en el momento oportuno y en forma aseada y decente. }\end{array}$ \\
\hline $\begin{array}{l}\text { Regla Mandela } \\
16\end{array}$ & Baño y ducha & $\begin{array}{l}\text { Las instalaciones de baño y de ducha serán adecuadas } \\
\text { para que todo recluso pueda bañarse o ducharse, e } \\
\text { incluso pueda ser obligado a hacerlo, a una tempera- } \\
\text { tura adaptada al clima, y con la frecuencia que exija la } \\
\text { higiene general }\end{array}$ \\
\hline $\begin{array}{l}\text { Regla Mandela } \\
17\end{array}$ & Higiene & $\begin{array}{l}\text { Todas las zonas del establecimiento penitenciario que } \\
\text { frecuenten los reclusos deberán mantenerse limpias y en } \\
\text { buen estado en todo momento. }\end{array}$ \\
\hline $\begin{array}{l}\text { Regla Mandela } \\
21\end{array}$ & $\begin{array}{l}\text { Hora de aire } \\
\text { libre. (Gestión } \\
\text { Penitenciaria) }\end{array}$ & $\begin{array}{l}\text { Todo recluso que no desempeñe un trabajo al aire libre } \\
\text { dispondrá, si las condiciones meteorológicas lo per- } \\
\text { miten, de al menos una hora al día de ejercicio físico } \\
\text { adecuado al aire libre. }\end{array}$ \\
\hline
\end{tabular}

Fuente: elaboración propia con base en las Reglas Mandela. 
En el ámbito del Sistema Interamericano, los Principios y Buenas Prácticas sobre la Protección de las Personas Privadas de Libertad en las Américas (2008) complementan algunas de las provisiones contenidas en las de las Reglas Mandela. En el Principio XII se establece que los lugares de albergue deberán disponer de espacio suficiente, exposición diaria a luz natural, ventilación, cama individual, condiciones de higiene, condiciones de descanso nocturno y calefacción de acuerdo con las condiciones climáticas. Esta regla también aclara que se deberá atender la situación de las personas con necesidades especiales (enfermos, personas con discapacidad, niños, mujeres embarazadas y lactantes, personas de la tercera edad, entre otros). Así mismo, el principio XIX establece la necesidad de separar el alojamiento en categorías por sexo, edad, la razón de su privación de libertad y la necesidad de protección de la vida e integridad de un interno. Por su parte, el principio XVII establece medidas para la reducción del hacinamiento, entre las cuales se establece que la información de la capacidad real del establecimiento deberá ser pública, accesible, actualizada y podrá ser impugnada, incluso mediante el trabajo de expertos independientes.

De lo anterior, es claro que las Reglas Mandela y los Principios y Buenas Prácticas de las Américas no establecen una norma universal que defina el área de alojamiento en detención. En consecuencia, cada país puede adaptar un mínimo de alojamiento que sea respetuoso de las Reglas Mandela y que sea funcional a la administración penitenciaria; además, varios gobiernos y organizaciones internacionales han implementado diferentes estándares de alojamiento y han hecho recomendaciones para su debido funcionamiento en las prisiones. A continuación, mostramos algunos ejemplos de este esfuerzo.

De acuerdo con el CICR, el espacio mínimo para que un detenido pueda dormir cómodamente, guardar sus cosas personales y desplazarse es de por lo menos de $5,4 \mathrm{~m}^{2}$ en celda individual y $3,4 \mathrm{~m}^{2}$ en celda colectiva. Así mismo, el espacio total de reclusión entre áreas privadas y comunes debe ser superior a $20 \mathrm{~m}^{2}$ (CICR, 2012, pp. 20-25; CICR, 2013). En el mismo sentido, la única razón por la que debería reducirse este espacio es en una situación de emergencia, caso en el cual se debería garantizar transitoriamente un mínimo de $2 \mathrm{~m}^{2}$ por recluso, aunque esta situación se limita única y exclusivamente a perturbaciones 
graves del orden público como, por ejemplo, conflictos armados internacionales o graves desastres naturales. Además, el CICR establece unos lineamientos complementarios al índice de espacio mínimo de alojamiento, particularmente en materia de camas, ventilación e iluminación que se resumen así:

Tabla 2. Requerimientos Mínimos de Alojamiento (CICR, 2012)

\begin{tabular}{|l|l|}
\hline Área total disponible & $20-30 \mathrm{~m}^{2}$ por persona \\
\hline Espacio mínimo de alojamiento & $3,4 \mathrm{~m}^{2}$ a $5,4 \mathrm{~m}^{2}$ por persona \\
\hline $\begin{array}{l}\text { Espacio de alojamiento en situaciones de crisis } \\
\text { graves }\end{array}$ & $\begin{array}{l}2 \mathrm{~m}^{2} \text { temporal }\left(1,6 \mathrm{~m}^{2} \text { de espacio libre }\right. \\
\text { en celda). Sólo en caso de emergencias o } \\
\text { conflictos armados de alta intesidad. }\end{array}$ \\
\hline Tamaño mínimo de camas & $(2 \times 0,8 \mathrm{~m}) 1,6 \mathrm{~m}^{2}$ por persona. \\
\hline Dimensiones de espacio entre camas & $\begin{array}{l}\text { Espacio mínimo entre piso y primer nivel: } 0,2 \\
\mathrm{~m} . \text { Espacio entre niveles: } 1,2 \mathrm{~m} .\end{array}$ \\
\hline Distancia entre camas & $1,5 \mathrm{~m}$. \\
\hline Ventilación & $\begin{array}{l}\text { Volumen aire por persona: } 3,5 \mathrm{~m} 3 \\
\text { de renovación de aire por hora. Área de } \\
\text { ventilación: } 0,025 \mathrm{~m}^{2} \text { por nivel de cama o } \\
\text { persona. }\end{array}$ \\
\hline Iluminación & $\begin{array}{l}\text { Abertura para luz por persona o nivel de cama: } \\
0,015 \mathrm{~m}^{2} .\end{array}$ \\
\hline
\end{tabular}

Fuente: CICR (2012).

Otros estándares internacionales son útiles para entender más criterios necesarios para la definición del alojamiento digno. En la Unión Europea las Reglas Penitenciarias Europeas (2006) remiten al estándar de alojamiento presentado por el Comité Europeo para la Prevención de la tortura y otros tratos crueles, inhumanos o degradantes, llamado los Estándares CPT (2015). El Comité Europeo contra la Tortura considera que el espacio mínimo que se debe garantizar a cada interno es de $6 \mathrm{~m}^{2}$ en celda individual y $4 \mathrm{~m}^{2}$ en celda colectiva sin incluir servicio hidrosanitario. Cuando la celda tiene servicio hidrosanitario, este debería ocupar entre 1 y $2 \mathrm{~m}^{2}$. Este estándar es un poco más alto que el contemplado por el CICR y evidencia las fluctuaciones, aunque sutiles, en materia de definición del alojamiento digno. 
Tabla 3. Estándares de alojamiento en diferentes normas técnicas y estudios internacionales

\begin{tabular}{|c|c|c|c|c|}
\hline & $\begin{array}{l}\text { CICR: "Agua, } \\
\text { saneamiento y } \\
\text { hábitat en las } \\
\text { cárceles" }\end{array}$ & $\begin{array}{c}\text { American } \\
\text { Correctional } \\
\text { Association }\end{array}$ & $\begin{array}{l}\text { CPT Standards } \\
\text { (Comité } \\
\text { Europeo contra } \\
\text { la Tortura) }\end{array}$ & $\begin{array}{l}\text { Reino Unido. } \\
\text { Acomodación } \\
\text { certificada. }\end{array}$ \\
\hline $\begin{array}{c}\text { Espacio mínimo } \\
\text { de alojamiento } \\
\text { en celda } \\
\text { individual }\end{array}$ & $5,4 \mathrm{~m}^{2}$ & $\begin{array}{l}\mathbf{3 , 2 5} \mathbf{~ m}^{2} \text { de espacio } \\
\text { libre en el suelo. } \\
(1,6 \mathrm{~m} \text { de área de } \\
\text { cama) }\end{array}$ & $6 \mathrm{~m}^{2}$ & $\begin{array}{c}\text { Variable } \\
\text { Aprox. } 7,2 \mathrm{~m}^{2}\end{array}$ \\
\hline $\begin{array}{l}\text { Espacio mínimo } \\
\text { de alojamiento } \\
\text { en celda } \\
\text { colectiva (por } \\
\text { persona) }\end{array}$ & $3,4 \mathrm{~m}^{2}$ & $\begin{array}{l}\mathbf{2 , 3 2} \mathbf{~ m}^{2} \text { de espacio } \\
\text { libre en el suelo. }\end{array}$ & $\begin{array}{c}\text { Área: } 4 \mathrm{~m}^{2} . \\
\text { Altura: } 2,5 \mathrm{~m}\end{array}$ & $\begin{array}{c}\text { Variable } \\
\text { Aprox. 3,6m2 }\end{array}$ \\
\hline $\begin{array}{l}\text { Gestión del } \\
\text { espacio }\end{array}$ & $\begin{array}{l}\text { Corte Constitu- } \\
\text { cional establece } \\
\text { un régimen } \\
\text { diferencial. } \\
\text { Entre más horas } \\
\text { en celda, más } \\
\text { grande debe ser } \\
\text { el espacio. Ver } \\
\text { sección } 3\end{array}$ & $\begin{array}{l}\text { Si la persona per- } \\
\text { manece en celda } \\
\text { individual más de } 10 \\
\text { horas al día: } \mathbf{6}, \mathbf{5} \mathbf{~ m}^{\mathbf{2}} \\
\text { Si la persona perma- } \\
\text { nece en celda colec- } \\
\text { tiva más de } 10 \text { horas } \\
\text { al día: } \mathbf{4 , 6} \mathbf{~ m}^{\mathbf{2}}\end{array}$ & - & - \\
\hline $\begin{array}{l}\text { Espacio mínimo } \\
\text { hidrosanitarios }\end{array}$ & Entre 1 y $2 \mathrm{~m}^{2}$ & & Entre 1 y $2 \mathrm{~m}^{2}$ & $\begin{array}{l}\text { Los ejemplos } \\
\text { muestran bate- } \\
\text { rías sanitarias de } \\
\text { aprox. } 2 \mathrm{~m}^{2}\end{array}$ \\
\hline
\end{tabular}

Fuente: elaboración propia.

Los estándares del Comité Europeo contra la Tortura incluyen dos disposiciones flexibles para que este mínimo de espacio cumpla con mínimos de antropometría y salud pública. En primer lugar, debe existir un espacio de mínimo 2 metros entre paredes del alojamiento, una medida que permite descartar celdas con corredores tan pequeños que representan un riesgo en caso de emergencia. En segundo lugar, la altura mínima de los alojamientos debe ser de $2,5 \mathrm{~m}^{2}$, de manera que se garantice una libre circulación del aire y se permita a las personas altas caminar libremente en el alojamiento.

Si bien los países pueden adoptar dentro de sus regulaciones domésticas los estándares internacionales propuestos por el CICR o por los estándares CPT, estos instrumentos no son vinculantes en el Derecho 
Internacional y por lo tanto los países pueden diseñar sus propios estándares mínimos de alojamiento, siempre y cuando sean coherentes con los mínimos establecidos en las Reglas Mandela. En este sentido, países como Estados Unidos o el Reino Unido han establecido sus propias normas técnicas, usando metodologías distintas para definir los estándares que deben cumplirse en materia de espacio y ocupación.

Por ejemplo, la Asociación Correccional de Estados Unidos (ACA) ha publicado unos estándares penitenciarios (ACA, 2000) ${ }^{12}$ que recopilan una batería de estándares diseñados para crear un certificado de "excelencia en la detención" (ACA, 2007), el cual es equivalente a un certificado de calidad que permite a las cárceles mejorar sus prácticas penitenciarias a partir de test periódicos. En materia de alojamiento, estos estándares establecen un mínimo de 35 pies $^{2}\left(3,25 \mathrm{~m}^{2}\right)$ en celda individual y 25 pies $^{2}$ $\left(2,32 \mathrm{~m}^{2}\right)$ en celda colectiva, salvo que el confinamiento diario dure más de 10 horas, en cuyo caso el mínimo es de $3,25 \mathrm{~m}^{2}$ (ACA, 2010). Además, los estándares de la ACA traen disposiciones en materia de gestión del riesgo y manejo de emergencias que son innovadoras respecto al resto de estándares expuestos. Entre ellos, establece la necesidad de contar con alojamientos libres de humo, así como una serie de indicadores para la resolución de emergencias, que incluyen un plan de emergencias, un plan de evacuación inmediata de los internos en caso de necesidad y una exigencia de que todo espacio con más de 50 personas debe tener dos salidas. También agrega provisiones de manejo de incendios que incluyen la prohibición de tener materiales inflamables en las celdas, así como equipamiento para mantener la luz y logística central de la cárcel durante una emergencia.

Otro ejemplo que puede ser útil para entender una forma diferente de abordar el cumplimiento de los estándares de alojamiento es el del Reino Unido. El Ministerio de Justicia del Reino Unido aplica una "acomodación certificada por prisionero" (2011), que es revisada a través de una lista de chequeo al momento que la persona ingresa a su primer día de reclusión. Los mínimos de alojamiento en este caso se definen por

12 De acuerdo con Susanna Chung (2000), hasta finales de la década de los noventa, las normas ACA han sido aceptadas en Estados Unidos como la "norma que prevalece" para medir el hacinamiento. 
el oficial que certifica el alojamiento, pero en principio no establece un estándar mínimo en metros cuadrados; en contraste, establece diferentes ejemplos de celdas que cumplen con la acomodación certificada dependiendo de las condiciones de seguridad, clima y necesidades funcionales para las que será usado el alojamiento. Los diferentes ejemplos de alojamientos certificados dependen de diferentes factores, pero en términos generales suelen estar cerca de los 3,4 $\mathrm{m}^{2}$ por persona en celda colectiva que recomienda el CICR. Finalmente, existen normatividades diferenciales con ajustes razonables para internos con riesgo de lastimarse a sí mismos o a otros, y otra normatividad diferencial para personas con discapacidad (Ministerio de Justicia del Reino Unido, 2011).

\section{La dimensión judicial del hacinamiento}

\section{Encarcelamiento masivo y hacinamiento}

El hacinamiento suele ser visto como un problema de escala nacional, es decir, que se desprende de los problemas político-criminales que enfrenta un país en concreto. Aunque, por supuesto, como ya lo señalaba Carranza para el caso latinoamericano (Carranza, 2012; Carranza, 2009), el hacinamiento es una de las manifestaciones más claras del desarreglo de una política criminal reactiva y populista, que acude irreflexivamente al uso generalizado de la prisión como principal respuesta a los conflictos sociales (Binder, 2010, pp. 213-229), también es el reflejo de la tendencia global más amplia del encarcelamiento masivo (Garland, 2011; Alexander, 2012; Hinton, 2016).

En ese sentido, los estudios que han descrito el fenómeno del encarcelamiento masivo han estudiado el papel de la prisión en el nuevo gobierno de la pobreza y la marginalidad (Waquant, 2000), su rol central en el control del delito en las sociedades caracterizadas por altas tasas de criminalidad y el impacto de la guerra contra las drogas en el sistema de justicia criminal y en poblaciones específicas (Tonry, 1994); además, muestran la revitalización de la prisión y su expresión en el crecimiento exponencial de las tasas de encarcelamiento a nivel comparado. Por esta razón, la interpretación del hacinamiento se debe enmarcar dentro de una 
discusión más amplia sobre el encarcelamiento masivo contemporáneo y el papel que cumplen o deberían cumplir los tribunales en su impulso o contención (Simon, 2011; Alexander, 2012).

El encarcelamiento masivo es un término acuñado por la sociología para describir las causas y consecuencias del enorme incremento de la población penitenciaria en los Estados Unidos entre 1972 y 2010, así como en otros países principalmente occidentales. El caso estadounidense es de lejos el más representativo. En efecto, la población carcelaria en Estados Unidos se quintuplicó en el corto periodo de 40 años, pasando de 380.000 reclusos en 1975 a algo más de 2,2 millones de personas encarceladas en 2017 (Garland, 2008; Waquant, 2002). Actualmente, Estados Unidos cuenta con la tasa de encarcelamiento más alta del mundo, representando un cuarto de la población penitenciaria mundial (ACLU, 2015; The Sentencing Project, 2016).

Aunque es difícil hablar de encarcelamiento masivo en América Latina, el aumento sostenido de las tasas de encarcelamiento en las últimas dos décadas es un fenómeno que se ha presentado en varios países de la región como Colombia, Brasil, El Salvador ${ }^{13}$ y Costa Rica, ${ }_{1}^{14}$ entre otros. Como se aprecia en la tabla 4 , el aumento de la tasa de encarcelamiento es particularmente dramático en países como Colombia o Brasil, en donde la población penitenciaria se ha duplicado o triplicado en menos de dos décadas (Iturralde, 2018, p. 11; Iturralde, 2010; Muller, 2011; Sozzo, 2016, pp. 301-324). Este fenómeno contrasta con la situación en países de Europa Occidental, donde la tasa de encarcelamiento se ha mantenido estable o sólo ha aumentado levemente a lo largo del tiempo. Con pequeñas diferencias en la escala del problema (como en el caso chileno), el encarcelamiento masivo es un problema general del contexto latinoamericano: como lo señala Sozzo (2016), prácticamente "[...] todos los países sudamericanos tienen tasas de encarcelamiento superiores a los 150 presos cada 100.000 habitantes".

13 La tasa encarcelamiento de El Salvador era en 2000 de 132 por 100.000 habitantes. En 2016, la tasa fue de 579 por 100.000 habitantes (International Centre for Prison Studies, 2017).

14 La tasa encarcelamiento de Costa Rica era en 2000 de 193 por 100.000 habitantes. En 2016, la tasa fue de 370 por 100.000 habitantes (International Centre for Prison Studies, 2017). 
Tabla 4. Capacidad, población carcelaria y tasa de encarcelamiento por $\mathbf{1 0 0 . 0 0 0}$ habitantes en seis países

\begin{tabular}{|c|c|c|c|c|c|c|}
\hline \multirow{2}{*}{} & \multicolumn{2}{|c|}{ Colombia } & \multicolumn{2}{c|}{ Brasil } & \multicolumn{2}{c|}{ Chile } \\
\cline { 2 - 7 } & $\begin{array}{c}\text { Capacidad } \\
\text { (2018) }\end{array}$ & 79.236 & $\begin{array}{c}\text { Capacidad } \\
\text { (2016) }\end{array}$ & 408116 & $\begin{array}{c}\text { Capacidad } \\
\text { (2016) }\end{array}$ & 41034 \\
\cline { 2 - 7 } & Población & $\begin{array}{c}\text { Tasa } \\
\text { Encarcelamiento }\end{array}$ & Población & $\begin{array}{c}\text { Tasa } \\
\text { Encarcelamiento }\end{array}$ & Población & $\begin{array}{c}\text { Tasa } \\
\text { Encarcelamiento }\end{array}$ \\
\hline 2000 & 51.518 & 128 & 232.755 & 133 & 33.005 & 215 \\
\hline $\mathbf{2 0 0 2}$ & 52.936 & 127 & 239.345 & 133 & 34.901 & 222 \\
\hline $\mathbf{2 0 0 4}$ & 68.002 & 159 & 336.358 & 182 & 36.374 & 226 \\
\hline $\mathbf{2 0 0 6}$ & 60.021 & 136 & 401.236 & 212 & 39.417 & 240 \\
\hline $\mathbf{2 0 0 8}$ & 69.979 & 154 & 451.429 & 234 & 48.826 & 291 \\
\hline $\mathbf{2 0 1 0}$ & 84.444 & 181 & 496.251 & 253 & 54.628 & 320 \\
\hline $\mathbf{2 0 1 2}$ & 113.884 & 237 & 548.003 & 275 & 51.882 & 298 \\
\hline $\mathbf{2 0 1 4}$ & 113.623 & 231 & 622.202 & 307 & 45.501 & 257 \\
\hline $\mathbf{2 0 1 6}$ & 118.532 & 235 & 644.575 & 313 & 43.603 & 242 \\
\hline $\begin{array}{l}2018- \\
\text { Mayo }\end{array}$ & 118.118 & $\mathrm{X}$ & $\mathrm{x}$ & $\mathrm{x}$ & $\mathrm{x}$ & $\mathrm{X}$ \\
\hline
\end{tabular}

\begin{tabular}{|c|c|c|c|c|c|c|}
\hline & \multicolumn{2}{|c|}{ Estados Unidos } & \multicolumn{2}{|c|}{ Inglaterra/Gales } & \multicolumn{2}{|c|}{ España } \\
\hline & $\begin{array}{l}\text { Capacidad } \\
\text { (2016) }\end{array}$ & 2140321 & Capacidad & 75756 & Capacidad & 84478 \\
\hline & Población & $\begin{array}{c}\text { Tasa } \\
\text { Encarcelamiento } \\
\end{array}$ & Población & $\begin{array}{c}\text { Tasa } \\
\text { Encarcelamiento } \\
\end{array}$ & Población & $\begin{array}{c}\text { Tasa } \\
\text { Encarcelamiento }\end{array}$ \\
\hline 2000 & $1^{\prime} 937.482$ & 683 & 64.602 & 124 & 45,309 & 113 \\
\hline 2002 & $2^{\prime} 033.022$ & 703 & 70.861 & 135 & 50.537 & 122 \\
\hline 2004 & $2^{\prime} 135.335$ & 725 & 74.657 & 141 & 58.655 & 137 \\
\hline 2006 & $2 ' 258.792$ & 752 & 78.150 & 145 & 63.248 & 142 \\
\hline 2008 & 2'307.504 & 755 & 82.636 & 152 & 70.465 & 153 \\
\hline 2010 & $2^{\prime} 270.142$ & 731 & 84.725 & 153 & 76.701 & 165 \\
\hline 2012 & $2^{\prime} 228.424$ & 707 & 86.634 & 153 & 70.695 & 151 \\
\hline 2014 & 2'217.947 & 693 & 85.307 & 149 & 66.857 & 144 \\
\hline 2016 & $\mathrm{X}$ & $\mathrm{x}$ & 85.348 & 146 & 61.526 & 133 \\
\hline
\end{tabular}

Fuente: elaboración propia con información de World Prison Brief. (International Centre for Prison Studies, 2017).

Estudios influyentes sobre el encarcelamiento masivo han girado hacia el análisis de su dimensión judicial. Las precarias condiciones de reclusión generadas por la sobrepoblación penitenciaria y su impacto 
en la garantía de los derechos de las personas privadas de la libertad, en distintos contextos y momentos, han impulsado las acciones judiciales de reclusos y activistas dirigidas a contener la expansión del poder punitivo del Estado. En el contexto del litigio en materia penitenciaria, los tribunales asumen posiciones políticas concretas cuando en la construcción de los problemas jurídicos relacionan, de manera directa o indirecta, el hacinamiento y las condiciones de reclusión con la configuración de penas y tratos crueles, inhumanos y degradantes (Ariza, 2011). En este caso en particular, como en la labor de adjudicación en general, la construcción de los casos no es neutral y supone una toma de posición frente al conflicto en el que se decide intervenir (Kennedy, 1998). Las órdenes judiciales dirigidas a la ampliación del sistema como respuesta a la crisis de cupos muestran, por ejemplo, una posición conservadora en la que se fortalece la institución penitenciaria a costa de la implementación de remedios judiciales dirigidos a enfrentar la violación actual de derechos (Ariza, 2013; Huertas, 2015, pp. 15-24). Por su parte, las órdenes judiciales dirigidas a las excarcelaciones y la diminución de la población penitenciaria suponen una postura que buscar limitar de manera fuerte los excesos en el ejercicio del poder punitivo del Estado (Simon, 2016; Schlanger, 2013, pp. 165-215).

En esta sección quisiéramos reseñar brevemente el caso estadounidense y el colombiano, los cuales evidencian los retos que supone la judicialización del hacinamiento. Creemos que estos dos casos son importantes porque muestran claramente las tensiones dentro del desarrollo jurisprudencial a la hora de definir el hacinamiento y vincularlo con la violación de derechos. Igualmente, son casos emblemáticos de intervención judicial en el campo penitenciario que han generado intensas discusiones académicas y políticas sobre el alcance de la reforma estructural impulsada por los tribunales. ${ }^{15}$

15 Aunque las tensiones que se han presentado en estos casos son, por supuesto, contextualmente definidas, la importancia de los modelos de intervención judicial desarrollados en el caso colombiano, por ejemplo, se aprecia en su adopción por parte de otros tribunales de la región. Tal es el caso de las declaratorias de Estado de Cosas Inconstitucional en Perú y Brasil. (Tribunal Constitucional del Perú, Sentencia Nº 02579-2003; Superior Tribunal Federal de Brasil, ADPF 347/DF, 2015). 


\section{El caso estadounidense}

Jonathan Simon describe adecuadamente el desarrollo de la intervención judicial en el contexto estadounidense como un juicio al encarcelamiento masivo. En Mass Incarceration on Trial (Simon, 2016) se describe la historia de la intervención judicial en el sistema penitenciario estadounidense, desde los inicios de los años sesenta hasta el caso Brown vs. Plata, analizando cómo los jueces estadounidenses han tenido un papel cada vez más protagónico en el impulso de políticas públicas orientadas por el problema del hacinamiento (Simon, 2013). Dada la complejidad de este desarrollo, aquí apenas esbozamos sus lineamientos generales. ${ }^{16}$

La Corte Suprema de Estados Unidos tuvo una fase inicial de no intervención judicial, tomando como base la autonomía funcional del sistema penitenciario y la consecuente incapacidad de los jueces para incidir en su desarrollo. ${ }^{17}$ La doctrina Hands Off suponía entonces que los jueces se retiraban de un mundo penitenciario que consideraban ajeno a sus competencias. Una vez superada esta etapa, la jurisprudencia tanto de jueces federales como de la Corte Suprema de Justicia ha implementado distintas doctrinas para relacionar el hacinamiento, las condiciones de reclusión y la existencia de penas y tratos crueles, inhumanos y degradantes. ${ }^{18}$ Por ejemplo, en el caso Rhodes vs Chapman (1981), en el cual se alegaba que el doble acomodamiento, esto es, el hecho de albergar a dos o más prisioneros en celdas diseñadas originalmente para una persona, constituía en sí mismo un trato cruel, inhumano y degradante, la Corte Suprema de Justicia consideró que esta práctica en sí misma no constituía una violación de la Octava Enmienda y que por lo tanto era necesario evaluar si las condiciones de reclusión no contrariaban los estándares de

16 Para un análisis detenido del desarrollo jurisprudencial estadounidense hasta mediados de la década de 1980 en materia de prisiones y control del delito ver (Angelos, 1985; Feely, Rubin, 1999).

17 A esta doctrina se le llamó Hands-off doctrine y fue el estándar de la Corte Suprema durante mediados del siglo Xx hasta su finalización en el caso de la Corte Suprema de los Estado Unidos Cooper vs. Pate, 378 U.S. 546 (1964). (Singler \& Shook, 1995).

18 Como lo señala Susanna Chung, sólo hasta mediados de 1960 las cortes federales empezaron a invocar la Octava Enmienda para analizar los casos de individuos condenados y las condiciones de reclusión, impulsados por el caso Robinson vs. California de la Corte Suprema de Justicia, pues anteriormente consideraban que la administración penitenciaria era un asunto de competencia gubernamental o legislativa. (Chung, 2000, p. 2357). 
decencia que caracterizan a una sociedad democrática (Chung, 2000, p. 2359). Por ello, los demandantes debían evidenciar un componente objetivo que demostrara que la privación era lo suficiente grave como para negar condiciones mínimas de vida digna (Chung, 2000, p. 2360). Posteriormente, en el caso Wilson vs Seiter (1991), ${ }^{19}$ la Corte Suprema de Justicia añadió la exigencia de probar que, además de las condiciones objetivas, se presenta un componente subjetivo que consiste en la indiferencia deliberada de la administración penitenciaria para modificar las condiciones de reclusión. ${ }^{20}$ Como lo señala Chung (2000, p. 2361), la falta de claridad de la Corte Suprema sobre el contenido del estándar de decencia y su relación con el hacinamiento llevó a que las cortes federales desarrollaran diferentes doctrinas para establecer cuándo se presentaba una violación de la Octava Enmienda.

Una de estas doctrinas se conoce como Test de la totalidad de las condiciones, en el cual se debe demostrar que el conjunto de condiciones de reclusión alcanza tal gravedad como para considerarse como la imposición de una pena o trato cruel, inhumano y degradante (Chung, 2000). Así, los accionantes no sólo deben mostrar que el establecimiento en el que se encuentran recluidos opera por encima de su capacidad, lo cual en principio resultaba relativamente sencillo, sino probar que distintas falencias en la operación del sistema, en el acceso a programas de tratamiento, salud y deficiencias en el alojamiento, se acumulaban para generar el daño. Otras cortes federales han implementado el estándar de condiciones básicas, según el cual se deben identificar aquellos factores esenciales de la vida en prisión (alimentación, salud, seguridad personal y salubridad, entre otros) cuya violación automáticamente genera un TCID; bajo esta doctrina, el hacinamiento no se puede alegar como una violación de la Octava Enmienda a menos que incida en la violación de un factor básico (Chung, 2000, p. 2366).

19 Igualmente, Daniel Hall indica que la exigencia probatoria es de tal magnitud que supone, en la práctica, un obstáculo para el acceso a la justicia de los prisioneros. (Hall, 1993; Chung, 2000, p. 2361).

20 En todo caso, como lo señala Sharon Dolovich, la Corte Suprema de Justicia ya había sentado las bases de los criterios objetivos y subjetivos en Estelle vs. Gamble, 429 U.S. 97 (1976), cuya exigencia de demostrar una indiferencia deliberada de la administración sobre las condiciones se reitera en Farmer vs. Brennan, 511 U.S. 825 (1994), bajo la exigencia de probar el conocimiento del riesgo de daño (Dolovich, 2009). 
Por último, se encuentra la aproximación per se, según la cual el hacinamiento en sí mismo supone un TCID. Esta doctrina define casuísticamente el fenómeno, algunas veces como el simple exceso en la ocupación o exigiendo además elementos de gravedad adicional, como la violación de los estándares de decencia. En el caso Chavis us Rowe (1981), por ejemplo, la Corte de apelaciones del Séptimo Circuito de los Estados Unidos estableció que el alojamiento de cinco personas en una celda choca con las nociones básicas de dignidad y genera per se una violación de la Octava Enmienda (Chung, 2000, p. 2368). Resulta importante mencionar que, de acuerdo con Chung, esta aproximación no riñe con la doctrina expresada en Rhodes vs Chapman, en la medida en que no se concentra en el hacinamiento como tal sino en el tamaño de la celda y el espacio disponible para los internos (Chung, 2000, p. 2368-2370).

En todo caso, con la promulgación del Prison Litigation Reform Act (1997), que construye procedimientos especiales para la presentación de las acciones y la viabilidad de los remedios judiciales consistentes en excarcelaciones, el litigio sobre prisiones se hizo más estricto. Con todo, este instrumento se puso en funcionamiento en el más reciente y conocido caso Brown vs Plata. ${ }^{21}$ En este caso -el último y quizás más conocido en el contexto latinoamericano- se establece que la sobrepoblación penitenciaria impide el adecuado funcionamiento del sistema, en cuanto a la prestación de servicios esenciales en salud y salubridad para la conservación de la vida de los internos. En este caso, y agotados los remedios judiciales posibles, proceden las órdenes de excarcelación hasta alcanzar el nivel de ocupación máximo, calculado en un 137,5\%, cuya superación supondría el colapso del sistema (Schlanger, 2013, pp. 165-215).

21 De acuerdo con Jonathan Simon, la sentencia de Brown v. Plata da un giro fundamental en el entendimiento de la octava enmienda y de las soluciones que una Corte puede implementar para exigir el fin del encarcelamiento masivo, llamando a esta sentencia una "cascada de dignidad" sobre la revitalización de la octava enmienda en el escenario constitucional. La Corte Suprema ordena la reducción de la población penitenciaria hasta el 137\% de hacinamiento, ante el hallazgo de que varias prisiones "Supermax" se encontraban insosteniblemente hacinadas, no contaban con servicios mínimos de resocialización y ni siquiera fueron construidas para disponer de un servicio básico de salud. (Simon, 2016, p. 134-145). 


\section{El caso colombiano: el estado de cosas inconstitucional}

En el caso de la intervención de la Corte Constitucional colombiana en el sistema penitenciario y carcelario también se puede apreciar la variación en la postura judicial sobre el hacinamiento. Lo primero que habría que señalar es que la Corte no vincula de manera explícita los casos sobre prisiones con la prohibición de imponer penas y tratos crueles, inhumanos y degradantes, aunque mencione en algunas sentencias que ciertas condiciones de reclusión podrían configurarlos. Las principales doctrinas utilizadas por la Corte Constitucional de Colombia para resolver las acciones interpuestas por las personas privadas de la libertad son la relación especial de sujeción y el régimen diferenciado de derechos fundamentales (Ariza, 2013), y es sólo hasta 1998 cuando decide intervenir estructuralmente en el sistema bajo la declaratoria de la existencia de un Estado de Cosas Inconstitucional (ECI) en la sentencia T-153 de 1998. ${ }^{22}$ Esta primera intervención estructural de la Corte considera que el hacinamiento es el problema central del sistema, del cual se desprenden las demás violaciones de derechos, y por ello las órdenes están orientadas hacia el aumento de la capacidad de albergue del sistema, cuya consecuencia política última es el fortalecimiento y legitimación de la prisión (Ariza, 2013).

Años después, y ante una nueva oleada de litigio que pedía revisar la efectividad de las órdenes emitidas en la sentencia T-153 de $1998{ }^{23}$ la Corte Constitucional declara nuevamente un ECI en el sistema a través de la sentencia T-388 de 2013 y, en este, se presenta una lectura distinta del papel del hacinamiento. En primer lugar, la Corte Constitucional

22 Como lo señala la Corte: "Esta corporación ha hecho uso de la figura del estado de cosas inconstitucional, con el fin de buscar remedio a situaciones de vulneración de los derechos fundamentales que tengan un carácter general, en tanto que afectan a multitud de personas, y cuyas causas sean de naturaleza estructural, es decir que, por lo regular, no se originan de manera exclusiva en la autoridad demandada y, por lo tanto, su solución exige la acción mancomunada de distintas entidades" (Corte Constitucional de Colombia, Sentencia T-153/1998, M.P Eduardo Cifuentes Muñoz).

23 Un ejemplo de esta oleada de litigio se ve reflejada en el Auto 041 de 2011 de la Corte Constitucional, que deniega una solicitud del Grupo de Derecho de Interés Público de la Universidad de Los Andes "con el objetivo de hacer un llamado [...] para que la Corte ordene las medidas necesarias para darle cumplimiento a la sentencia T-153/1998 [...] mediante la cual se declaró la existencia de un estado de cosas inconstitucional en las cárceles". 
establece la relación entre hacinamiento carcelario y la violación de derechos de una manera compleja, en los siguientes términos:

El hacinamiento no es el único problema del sistema penitenciario y carcelario del país. Sin embargo, toda la inversión presupuestal se ha dirigido únicamente a la creación de nuevos cupos carcelarios. Esta estrategia es insuficiente, ya que se abandona la atención de otras problemáticas igual de importantes [...]. Deben atenderse otras problemáticas diferentes al hacinamiento para superar la violación masiva de los derechos de los presos en Colombia como, por ejemplo, la adecuación y puesta en práctica de programas de resocialización, la adecuada prestación de los servicios de salud, la adecuada prestación de los servicios de agua potable, la prevención de enfermedades al interior de los penales, la adecuación de espacios salubres e higiénicos donde los presos puedan alimentarse y satisfacer sus necesidades básicas con dignidad, la garantía de seguridad y vigilancia para los presos, entre otros. (Sentencia T-388 de 2013, M.P. María Victoria Calle)

En segundo lugar, la Corte Constitucional acepta que la intervención judicial estructural no puede estar atrapada por el discurso del hacinamiento y que, por lo tanto, los remedios judiciales efectivos no pueden estar dirigidos per se al aumento de la capacidad de albergue del sistema, sino a la formulación de una política criminal adecuada que logre su equilibrio. Lo anterior ha sido formulado por la Corte como la regla de equilibrio, la cual expresa en los siguientes términos: "sólo se podrá autorizar el ingreso de personas al centro de reclusión si y sólo si (i) el número de personas que ingresan es igual o menor al número de personas que salgan del establecimiento de reclusión, durante la semana anterior, por la razón que sea, y (ii) el número de personas del establecimiento ha ido disminuyendo constantemente, de acuerdo con las expectativas y las proyecciones esperadas" (Sentencia T-388 de 2013, parr. 9.1.2.4.1).

La última y más reciente declaratoria de $\mathrm{ECI}$ en el sistema penitenciario colombiano, por medio de la sentencia T-762 de 2015, redefine el papel del hacinamiento en la violación de derechos, tratándolo como un factor que ha de ser medido en función de las obligaciones estatales de garantizar condiciones mínimas de vida digna para las personas privadas de la libertad. A pesar del rol fundamental en el mal desempeño institucional 
y sus efectos en la violación de derechos, desde el punto de vista del enfoque de esta intervención judicial, la cual se basa fundamentalmente en una reforma estructural orientada a la creación de normas técnicas de reclusión, una línea base de indicadores y una estructura de seguimiento al cumplimiento de las órdenes que permita levantar paulatinamente el $\mathrm{ECI}$, el hacinamiento, como espacio de reclusión digno, tiene la misma entidad que la garantía, por ejemplo, de recibir un mínimo de agua potable y alimentación. En este sentido, la Corte Constitucional realiza un ejercicio similar al descrito en el estudio de caso estadounidense, al evaluar la totalidad de las condiciones de reclusión bajo la doctrina del ECI para establecer los niveles de garantía de derechos y, en función de esto, la superación paulatina del ECI. La Corte señala lo anterior en los siguientes términos:

[...] el proceso de superación del ECI [...] tendrá varias etapas. La primera, será una fase inicial en la que las medidas de política pública empezarán su implementación; la segunda, una fase intermedia hacia la renovación de la política criminal; y la tercera, de solidificación de una política criminal articulada y eficiente; y, la cuarta, de superación del carácter masivo del compromiso de derechos". (Sentencia T-762 de 2015, parr. 126-127)

Ante esta situación, las órdenes diseñadas por la Corte Constitucional muestran la aplicación de los estándares y criterios analizados en este texto, particularmente a través de la adopción de los estándares del CICR, que fueron adoptados por la Corte Constitucional en la Sentencia T-762 de 2015. ${ }^{24}$ Para la Corte, la medición del espacio digno no sólo

24 La Corte Constitucional ordena el cumplimiento de un estándar de alojamiento mínimo en celda de $5,4 \mathrm{~m}^{2}$ en celda individual y $3,4 \mathrm{~m}^{2}$ en celda colectiva y matiza el cumplimiento de este estándar al número de horas que la persona permanece en el dormitorio: cuantas más horas dentro de celda, más grande debe ser el espacio. Por ejemplo, una celda en la que la persona sólo pase 3 horas al aire libre deberá ser de mínimo $7,4 \mathrm{~m}^{2}$ en celda individual y 5,4 $\mathrm{m}^{2}$ en celda colectiva.

La Corte Constitucional complementa este espacio mínimo de alojamiento con un espacio total de reclusión que incluye áreas comunes y alojamiento, el cual debe ser de mínimo $20 \mathrm{~m}^{2}$. Para calcular este espacio, al área total del patio o la cárcel se le debe restar "aquellas zonas destinadas a la gestión de la administración y del entrenamiento o estancia de la guardia, estableciendo el área destinada al uso de los reclusos y accesible en condiciones de normalidad (Sentencia T-762/2015, parr. 125-127). 
se refiere a la medición del nivel de ocupación, sino que exige tener en cuenta el tiempo que la persona permanece en celda, tal como se aprecia en la tabla 5 .

Tabla 5. Relación tiempo de actividad externa a la celda y metraje mínimo de alojamiento. Sentencia T-762 de 2015

\begin{tabular}{|c|c|c|}
\hline \multirow{2}{*}{$\begin{array}{c}\text { Tiempo fuera de celda } \\
\text { (Horas) }\end{array}$} & \multicolumn{2}{|c|}{ Metraje $\left(\boldsymbol{m}^{2}\right)$} \\
\cline { 2 - 3 } & Celda Individual & Celda Colectiva \\
\hline 10 & $5,4 \mathrm{~m}^{2}$ & $3,4 \mathrm{~m}^{2}$ \\
\hline 6 & $6,4 \mathrm{~m}^{2}$ & $4,4 \mathrm{~m}^{2}$ \\
\hline 3 & $7,4 \mathrm{~m}^{2}$ & $5,4 \mathrm{~m}^{2}$ \\
\hline
\end{tabular}

Fuente: elaboración propia con base en la Sentencia T-762 de 2015 de la Corte Constitucional.

En la actualidad, la Corte Constitucional cuenta con una Sala Especial de Seguimiento de las condiciones de reclusión, que emite órdenes a través de autos y con base en un proceso institucional complejo. Este seguimiento supone que la superación del Estado de Cosas Inconstitucional se produce a través de distintas fases. En primer lugar, el diseño y cumplimiento de una línea base de indicadores que permita evaluar la garantía del estándar mínimo de vida digna en prisión, hasta la consolidación de unas normas técnicas de reclusión que midan integralmente el hacinamiento en términos que respondan a los estándares mínimos de reclusión que exige el derecho internacional. ${ }^{25}$

En consecuencia, la Corte Constitucional continúa siendo un actor activo en la superación de la crisis carcelaria, ordenando al gobierno nacional en diferentes autos de seguimiento la realización de informes periódicos sobre el avance en la superación de la crisis (Auto 121 de 2018, Auto del 10 de agosto de 2017). En su última intervención, la Corte Constitucional ordena citar a audiencia pública a todas las entidades públicas que participan de la política criminal, para rendir informe de los avances en las órdenes de la sentencia T-762 de 2015 y el Auto 121 de 2018 (Auto 613 de 2018), así como a organizaciones sociales y miembros

25 En este contexto, importantes esfuerzos se han realizado en Colombia por diseñar una línea base de indicadores que midan todos los aspectos de la vida en reclusión, ver: (Ariza, Iturralde, Torres, et al, 2017). 
del mundo académico, lo cual demuestra cómo la Corte Constitucional sigue ejerciendo un control fuerte de los resultados de cada entidad en la superación del hacinamiento carcelario.

\section{Conclusión}

Gracias a los avances en la intervención judicial para enfrentar la crisis carcelaria, el entendimiento político y jurídico del hacinamiento ha adquirido un nuevo impulso como una problemática transversal a los sistemas penitenciarios. El hacinamiento, política y jurídicamente, ha permitido tanto a los operadores jurídicos como a activistas, jueces e instituciones públicas hacer inteligible ante la opinión pública la crisis penitenciaria, así como avanzar en la agenda de la reforma de la política criminal. El hacinamiento es el lenguaje dominante de la crisis penitenciaria, por ello, entender los retos jurídicos y políticos que supone definirlo es un aspecto central de la protección judicial de las condiciones de reclusión de las personas privadas de la libertad.

Como se ha mostrado a lo largo de este texto, el hacinamiento es un concepto particularmente elusivo en su dimensión normativa, lo cual permite un margen de movilidad política para los actores involucrados en la política criminal. Por ello, el hacinamiento suele ser entendido desde diferentes dimensiones: como capacidad instalada, como densidad de población o como un estándar integral de alojamiento. En ese sentido, este texto ha presentado una amplia gama de aproximaciones normativas al hacinamiento, mostrando las principales fuentes normativas y técnicas que existen en la literatura para medir integralmente las condiciones de reclusión y su relación con el alojamiento.

Desde su dimensión judicial, el texto presentó el caso estadounidense y el caso colombiano como ejemplos donde se muestran claramente las tensiones dentro del desarrollo jurisprudencial para definir el hacinamiento y vincularlo con una violación de derechos. Ante la complejidad normativa de definir el hacinamiento, los jueces que intervienen en el sistema penitenciario se encuentran en una situación en la que cuentan con un margen político para definir si interpretan la problemática del hacinamiento como un asunto que se reduce a la 
medición de la capacidad del sistema, o si se entiende el hacinamiento como un fenómeno que "en sí mismo" constituye un trato cruel, inhumano o degradante.

La sombra del hacinamiento ha cubierto de manera importante la forma en que los jueces construyen los casos sobre el alcance de los derechos de las personas privadas de la libertad. El ámbito de protección varía en función del alcance que se le da al fenómeno y su relación con la interpretación del significado de vivir dignamente en prisión. Esperamos que este giro en la comprensión del fenómeno abra espacio a otras formas de imaginar las respuestas a la crisis del hacinamiento más allá de la ampliación del sistema como resultado de la intervención estructural.

\section{Referencias}

Albrecht, H. (2012). Prison Overcrowding- Finding Effective Solutions. Strategies and Best Practices in Correctional Facilities. Freiburg: Max Plank Institute for Foreign and International Criminal Law. Recuperado de https://www.mpicc.de/ shared/data/pdf/research_in_brief_43_-_albrecht_prisonvercrowding.pdf

Alexander, M. (2012). The New Jim Crow, Mass Incarceration in the Age of Colorblindness. Nueva York: The New Press.

American Correctional Association. (2010). Core Jail Standards, 2010 edition. Recuperado de http://correction.org/wp-content/uploads/2014/09/CoreJail-Standards-as-printed-June-2010.pdf.

American Correctional Association. (2007). Manual of Accreditation, Policy and Procedure. Recuperado de https://www.aca.org/ACA_Prod_IMIS/docs/ standards\%20and\%20accreditation/ALM-1-3_15_17-Final.pdf.

Angelos, C. \& James B. J. (1985). Prison Overcrowding and the Law. The Annals of the American Academy of Political and Social Science, 478(1), 100-112. Recuperado de www.jstor.org/stable/1045952

Ariza, L. (2013). Economic and Social Rights, Prisons, and the Colombian Constitutional Court: Intervention in the Penitentiary System in Colombia. En D. Bonilla Maldonado, (ed.), Constitutionalism of The Global South: The activist tribunals of India, South Africa and Colombia (pp. 129-163). Cambridge, Inglaterra: Cambridge University Press.

Ariza, L., Iturralde, M. \& Torres, M. (2017). Línea Base de Derechos Humanos para el Sistema Penitenciario y Carcelario. Bogotá: Ministerio de Justicia del Derecho. 
Recuperado de https://grupodeprisiones.uniandes.edu.co/images/MediaPrisiones2018/Publicaciones/LineaBaseDDHHparaSPC2017-tomoI.pdf

Ariza, L. E Torres, M. (2019). Constitución y Cárcel: La judicialización del mundo penitenciario en Colombia. Direito \& Práxis, 10(1), 630-660.

Ariza, L. (2011). Reformando el infierno: los tribunales y la transformación del campo penitenciario en América Latina. En Los muros de la infamia, prisiones en Colombia y América Latina (pp. 18-110). Bogotá, Colombia: Universidad de Los Andes.

Archila, J. E Hernández, N. (2015). Subrogados y hacinamiento carcelario. Respuesta del legislador del año 2014 frente a la situación carcelaria en Colombia. Misión Jurídica, 9, 199-227.

Bleich, J. (1989). The Politics of Prison Crowding. Recuperado de http://scholarship. law.berkeley.edu/californialawreview/vol77/iss5/4

Blumstein, A. (2011). Bringing Down the U.S. Prison Population. The Prison Journal Supplement to, 91(3) 12S-26S.

Blumstein, A. (1982). On the Racial Disproportionality of United States' Prison Populations. Journal of Criminal Law and Criminology, 73(3), 1259-1282.

Bolduc, A. (1985). Jail Crowding. The Annals of the American Academy of Political and Social Science, 478(1), 47-57. Recuperado de https://www.jstor.org/stable/1045948?seq=1\#page_scan_tab_contents

Carranza, E. (2012). Situación penitenciaria en América Latina y el Caribe, ¿Qué hacer? San José de Costa Rica: ILANUD, Anuario de Derechos Humanos.

Carranza, E. (ed.). (2009). Cárcel y justicia penal en América Latina: cómo implementar el modelo de derechos y obligaciones de las Naciones Unidas, México D.F.: Siglo XXI Editores, ILANUD, Instituto Raoul Wallenberg de Derechos Humanos y Derecho Humanitario.

Carranza, E., (Ed.). (2001). Justicia penal y sobrepoblación penitenciaria: respuestas posibles. México D.F.: ILANUD y Siglo XXI Editores.

Centro de Estudios Legales y Sociales (CELS). (2008), Litigio estratégico y derechos humanos, la lucha por el derecho, Buenos Aires: Siglo XXI. Recuperado de http:// www.cels.org.ar/common/documentos/la_lucha.pdf

Chung, S. (2000). Prison Overcrowding: Standard in defining Eight Amendment Violations. Fordham Law Review, 68(6), 2361-2400. Recuperado de https:// ir.lawnet.fordham.edu/cgi/viewcontent.cgi?article $=3653 \xi$ context $=$ flr

Comité Internacional de la Cruz Roja (CICR). (2012). Agua Saneamiento y Hábitat en las cárceles; Guía Principal. Ginebra: Pier Giorgio Nembrini.

Comité Internacional de la Cruz Roja (CICR). (2013). Agua Saneamiento y Hábitat en las cárceles; Guía Complementaria. Ginebra: Comité Internacional de la Cruz Roja. 
Clear, T. R. E Schrantz, D. (2011). Strategies for Reducing Prison Populations. Prison Journal, 91(3), 138S-159S.

European Committe on Crime Problems, Council for Penological Cooperation. (2015). White Paper on Prison Crowding. Estrasburgo: Document prepared by the Directorate General, Human Rights and Rule of Law.

Congreso le los Estados Unidos. (1997). The Prison Litigation Reform Act (PLRA). Consejo De Europa, Comité para la Prevención de la Tortura. (2015). Living Space per Prisoner in Prison Eestablishments: CPT standards. Estrasburgo: Recuperado de http://www.refworld.org/docid/56e01b4d4.html

Consejo De Europa (2006). Reglas Penitenciarias Europeas, aprobadas en 952nd sesión. Recuperado de https://search.coe.int/cm/Pages/result_details. aspx?ObjectID=09000016805d8d25

Corte Constitucional de Colombia. Auto 041 de 2011.

Corte Constitucional de Colombia. Sentencia T-153/1998, M.P Eduardo Cifuentes Muñoz.

Corte Constitucional de Colombia. Sentencia T-388/2013, M.P María Victoria Calle. Corte Constitucional de Colombia, Sentencia T-762/2015, M.P Gloria Stella Ortiz Delgado

Corte de Apelaciones del Séptimo Circuito de Estados Unidos (1981). Chavis v. Rowe, 643 F. 2d 1281 (1981).

Corte Suprema de Argentina (2005). Caso de "Verbitsky s/habeas corpus," V.856. XXXVIII, 3 de mayo de 2005.

Corte Suprema de los Estados Unidos (2011). Brown vs Plata et al, 563 U.S. 493. Corte Suprema de los Estados Unidos (1981). Rhodes vs Chapman, 452 U.S. 337. Corte Suprema de los Estados Unidos (1991). Wilson vs Seiter, 501 U.S. 294.

Davis, C. P. \& Epperson, M. W. (2014). From Mass Incarceration to Smart Decarceration. Center for Social Development. CSD Working Papers No. 14-312014.

Dolovich, S. (2009). Cruelty, Prison Conditions, and the Eighth Amendment. New York University Law Review, 84(4), 881-979.

Feely, M. E Rubin, N. (1999), Judicial Policy Making and the Modern State: How the Courts Reformed America's Prisons. Nueva York: Cambridge University Press. Garland, D (2007). Crimen y castigo en la modernidad tardía. Bogotá: Siglo del Hombre Editores.

Garland, D. (2001). Mass Incarceration, Social Causes and Consequences. Londres: SAGE.

Gonzalez Bartomeu, J. F. (2016). Prisons and Prisoners' Rights. En J. F. Gozalez Bartomeu \& Gargarella, R., The Latin American casebook: courts, constitutions and rights (pp. 80-103 ). Nueva York, Estados Unidos: Routledge. 
Griffiths, C. \& Murdoch, D (2009). Strategies and Best Practices against Overcrowding in Correctional Institutions. Vancuver: The International Centre for Criminal Law Reform and Criminal Justice.

Hall, D. Y. (1993). Eighth Amendment, Prison Conditions and Social Context. Missouri Law Review, 58(1), 207-236. Recuperado de http://scholarship.law. missouri.edu/mlr/vol58/iss $1 / 10$

Hernández, N. (2018). El derecho penal de la cárcel. Una mirada al contexto colombiano con base en el giro punitivo y la tendencia al mayor encarcelamiento. Bogotá: Siglo del hombre editores, Universidad de los Andes y EAFIT.

Hinton, E. K. (2016). From the War on Poverty to the War on Crime: The Making of Mass Incarceration in America. Cambridge: Harvard University Press.

Huertas, O. (2015). Sistema penal y hacinamiento carcelario. Análisis al estado de cosas inconstitucionales en las prisiones colombianas. Revista jurídica de derecho, 2(3), 15-24.

Iturralde, M. (2008). Emergency Penality and Authoritarian Liberalism: Recent Trends in Colombian Criminal Policy. Theoretical Criminology, 12(3), 377-397. Doi: doi.org/10.1177/1362480608093312

Iturralde, M. (2018). Neoliberalism and its Impact on Latin American Crime Control Fields. Theoretical Criminology, 22(1), 1-20.

Iturralde, M. (2010). Democracies without Citizenship: Crime and Punishment in Latin America. New Criminal Law Review, 13(2), 309-332.

Kennedy, D. (1998). A Critique of Adjudication: Fin de Siecle. Cambdridge: Harvard University Press.

Ministerio de Justicia del Reino Unido. (2012). Certified Prisoner Accomodation, Reino Unido: PSI 17/2012. Recuperado de https://www.justice.gov.uk/downloads/ offenders/psipso/psi-2012/psi-17-2012-certified-prisoner-accommodation. doc [visitado el 28.06.2018]

Ministerio de Justicia del Reino Unido, PSI 64/2011: Management of Prisoners at Risk of Harm to Self, to Others and from Others (Safer Custody).

Mullen, J. (1985). Prison Crowding and the Evolution of Public Policy. The annals of the American Academy of Political and Social Science, 478(1), 31-46.

Müller, M. M. (2011). The Rise of the Penal State in Latin America. Contemporary Justice Review, 15(3), 1-20.

Organización de Estados Americanos. (2008). Principios y buenas prácticas sobre la protección de las personas privadas de Libertad en las Américas, Adoptados por la CIDH en $131^{\circ}$ período ordinario.

Pfaff, J. (2015). Locked In: The True Causes of Mass Incarceration-and How to Achieve Real Reform. Nueva York: Basic books. 
Rodley, N. (2011). The Treatment of Prisoners in International Law. Londres: Oxford University Press.

Rodríguez, M. (2015). Hacinamiento penitenciario en América Latina: Causas y estrategias para su reducción. México D.F: CNDH.

Schlanger, M. (2013). Plata vs Brown and Realignment: Jails, Prisons, Courts, and Politics. Harvard Civil Rights-Civil Liberties Law Review, 48(1), 165-215. Recuperado de https://repository.law.umich.edu/cgi/viewcontent.cgi?artic $\mathrm{le}=1462$ Econtext $=$ articles

Sigler, R. E Shook, C. (1995). The Federal Judiciary and Corrections: Breaking the "Hands-Off" Doctrine. Criminal Justice Policy Review, 7(3-4), 245-254.

Simon, J. (2016). Mass Incarceration on Trial: A Remarkable Court Decision and the Future of Prisons in America. Nueva york: The New Press.

Simon, J. (2011). Fear and loathing in late modernity: Reflections on the cultural sources of mass imprisonment in the United States. En D. Garland, (ed.), Mass Imprisonment: Social Causes and Consequences, (pp. 15-26). Londres, Inglaterra: Sage.

Simon, J. (2013). The Return of the Medical Model: Disease and the Meaning of Imprisonment from John Howard to Brown v. Plata. Harvard Civil Rights-Civil Liberties Law Review, 48(1), 217-256.

Sozzo, M. (2016). Democratization, politics and punishment in Argentina". Punishment and Society, 18(3), 301-324.

Superior tribunal Federal de Brasil. (2015). Petição Inicial da Arguição de Descumprimento de Preceito Fundamental ADPF No 347/DF.

Tonry, M. (1994). Race and the War on Drugs. University of Chicago Legal Forum: Recuperado de http://chicagounbound.uchicago.edu/uclf/vol1994/iss 1/4 https://chicagounbound.uchicago.edu/cgi/viewcontent.cgi?article $=1155 \mathrm{E}-$ context $=$ uclf

Tribunal Constitucional del Perú. (2004). Sentencia en el Expediente Nº 02579 2003-HD/TC.

Oficina de las Naciones Unidas para la Droga y el Delito (UNODC). (2013). Manual de estrategias para reducir el hacinamiento. Nueva York: Serie de manuales de justicia penal, Naciones Unidas. Recuperado de https://www.unodc.org/documents/ justice-and-prison-reform/UNODC_HB_on_Overcrowding_ESP_web.pdf

Wacquant, L. (2000). Las cárceles de la miseria. París: Manantial.

Zorro, A., Acosta, C. E Hernández, N. (2016). Un enfoque económico de la detención preventiva. Crecimiento de la población reclusa y hacinamiento carcelario en el tránsito del sistema penal acusatorio colombiano (2003-2008). E. Lozano (coord.). Teoría y puesta en práctica del análisis económico del derecho colombiano, (pp. 251-292). Bogotá, Colombia: Universidad de los Andes. 